\title{
Should prostacyclin be wrapped inside a fatty flap?
}

\author{
Ari A. Mennander, MD, PhD
}

From Tampere University Heart Hospital and Tampere University, Tampere, Finland.

Disclosures: Author has nothing to disclose with regard to commercial support.

Received for publication Feb 25, 2018; accepted for publication Feb 28, 2018; available ahead of print March 23, 2018.

Address for reprints: Ari A. Mennander, MD, PhD, Tampere University Heart Hospital, SDSKIR, PL 2000, Tampere, Finland (E-mail: ari.mennander@sydansairaala.fi).

J Thorac Cardiovasc Surg 2018;156:242-3

$0022-5223 / \$ 36.00$

Copyright (c) 2018 by The American Association for Thoracic Surgery

https://doi.org/10.1016/j.jtcvs.2018.02.068

Chronic myocardial infarction and associated ischemia induce a remodeling phase that compensates for the loss of viable cells, often leading to increased scarring and subsequent cardiac failure. Therapeutic healing of the ischemic myocardium encompasses increased formation of newly bulging capillaries during early angiogenesis and sustained arteriogenesis indicating effective neovascularization. ${ }^{1}$ Application of skeletal myoblasts on the myocardial infarction area has not been able to retain long-term arteriogenesis. Skeletal myoblasts may provoke arrhythmias of the scarring myocardium. ${ }^{1}$ The short half-life of many potentially therapeutic molecules restricts the clinical use of proangiogenic agents.

A synthetic prostacyclin agonist conjugated into a polymer (ONO-1301SR) affords retained effect and may surpass the strategic transition phase of angiogenesis to enforce arteriogenesis. $^{2,3}$ A superimposed omental flap may synergistically further enhance the healing effect of ONO1301SR during chronic myocardial infarction. ${ }^{1,4}$ In the current article by Yajima and colleagues, ${ }^{5}$ ONO-1301SR within the omentum was experimentally investigated to induce prolonged angiogenesis during chronic myocardial infarction in a mini-pig model. According to angiograms, pressure wiring, positron emission tomography, and histology, the combined treatment accelerated the development of CD31-positive collateral arteries, decreased microvasculature peripheral resistance, and increased flow reserve of the microvasculature and myocardial blood flow. Consistently, increased cardiac ejection fraction, attenuation of fibrosis, and swollen myocytes were observed. Sustained angiogenesis was confirmed by evaluating the gene expression profile of some proangiogenic mediators of the area around the infarction.

The induction of proangiogenic factors such as vascular endothelial growth factor, hepatocyte growth factor, and stromal cell-derived factor 1 were upregulated after the myocardial infarction without treatment. The increase of these mediators may indicate that angiogenesis is required to secure healing after chronic myocardial infarction. The expression of vascular endothelial growth factor and

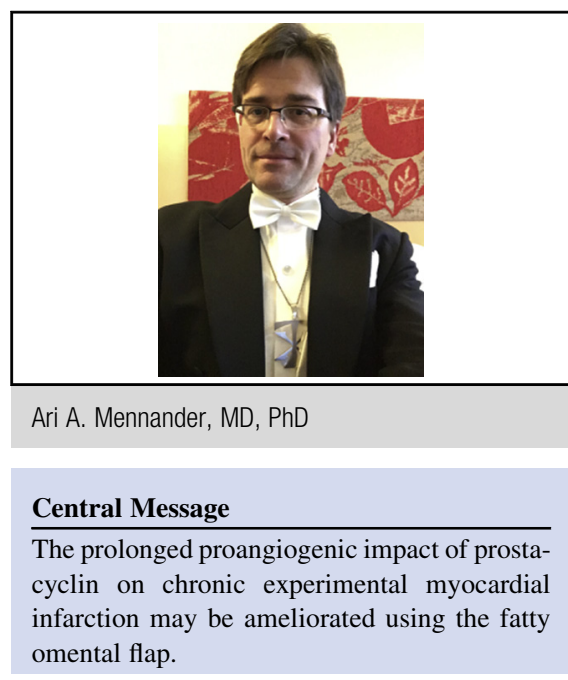

See Article page 229

fibroblast growth factor eventually decreased in the sham and the omentum only groups. The combined and the prostacyclin treatment alone enabled the continuous elevation of proangiogenic factors explaining the increased development of the collateral network during myocardial remodeling. It is conceivable that the prolonged induction of proangiogenesis by the combined prostacyclin plus omentum offered a beneficial healing milieu during chronic myocardial infarction.

The safety of the prostacyclin agonist has yet to be evaluated. In another study, a stable prostacyclin analogue was deleterious to cardiomyocytes increasing apoptosis and mouse mortality. ${ }^{6}$ In the current era of minimal invasive techniques especially in elective surgery, exploiting the omental flap through an extended sternal or additional wound may not be an attractive strategy. Even the technique of using the gastroepiploic artery as a coronary graft together with a small pedicle of omentum has mainly been abandoned. But what if the perivascular tissue around the internal thoracic artery graft would do the trick? Would the application of the prostacyclin agonist together with the fatty pedicle of the graft simulate the synergistic impact of the omental flap and secure sustained arteriogenesis? The Osaka research team has once again shown how close it may be for theory and experimental science to reach for a landmark in practice.

\section{References}

1. Angelini G, Caputo M, Madeddu P. Extending flaps lifts an infarcted heart toward repair. Mol Ther. 2015;23:223-5. 
2. Kubota Y, Miyagawa S, Fukushima S, Saito A, Watabe H, Daimon T, et al. Impact of cardiac support device combined with slow-release prostacyclin agonist in a canine ischemic cardiomyopathy model. J Thorac Cardiovasc Surg. 2014;147:1081-7.

3. Iwata H, Nakamura K, Sumi M, Ninomiya M, Sakai Y, Hirata Y, et al. Local delivery of synthetic prostacycline agonist augments collateral growth and improves cardiac function in a swine chronic cardiac ischemia model. Life Sci. 2009;85:255-61.

4. Kainuma S, Miyagawa S, Fukushima S, Pearson J, Chen YC, Saito A, et al. Cell-sheet therapy with omentopexy promotes arteriogenesis and im- proves coronary circulation physiology in failing heart. Mol Ther. 2015; 23:374-86.

5. Yajima S, Miyagawa S, Fukushima S, Sakai Y, Isohashi K, Watabe T, et al. A prostacyclin agonist and an omental flap increased myocardial blood flow in a porcine chronic ischemia model. J Thorac Cardiovasc Surg. 2018;156:229-41.e14.

6. Lian W-S, Chiou H-C, Lin H, Chen J-J, Cheng C-F. The prostaglandin agonist beraprost aggravates doxorubicin-mediated apoptosis by increasing iNOS expression in cardiomyocytes. Curr Vasc Pharmacol. 2015;13:54-63. 